\title{
MULTIVARIATE CALIBRATION METHOD FOR SIMULTANEOUS ESTIMATION OF FLUOCORTOLONE CAPROATE, FLUOCORTOLONE PIVALATE AND CINCHOCAINE HCL IN SUPPOSITORY
}

\author{
ÖZLEM AKSU DÖNMEZ ${ }^{a}$
}

\begin{abstract}
In this paper, the simultaneous quantitative assay of Fluocortolone caproate (FCC), Fluocortolone pivalate (FCP) and Cinchocaine $\mathrm{HCl}(\mathrm{CIN})$ in suppository has been reported as a simple alternative analytical method. A partial least squares (PLS-2) regression was used for resolution of the overlapped spectrophotometric signals from mixtures of the three drugs. A calibration set containing FCC, FCP and CIN was constructed by using $3^{3}$ full factorial design in the concentration range of $4.5-8.5,5-7$ and $8-12 \mu \mathrm{g} / \mathrm{mL}$, respectively. Absorption spectra were recorded in the range $240-350 \mathrm{~nm}$. To check the quality of the proposed method, it was applied to the determination of these compounds in synthetic mixtures and pharmaceutical formulation, suppository. The PLS-2 method yielded recoveries ranging from 91 to $106 \%$. The results compared well with those from the reported HPLC method.
\end{abstract}

Keywords: fluocortolone caproate, fluocortolone pivalate, cinchocaine $\mathrm{HCl}$, PLS

\section{INTRODUCTION}

Fluocortolone caproate (FCC) and fluocortolone pivalate (FCP) are glucocorticoids with anti-inflammatory activity used topically for various skin disorders [1]. Cinchocaine $\mathrm{HCl}(\mathrm{CIN})$ is a long-acting amide anaesthetic used for surface anaetsthesia for relief of pain [2]. The combination of these active compounds are used mostly to reduce the common syptoms caused by haemorrhoids.

There are a few studies in the literature describing the determination of fluocortolone and its esters FCC and FCP using thin layer chromatography

\footnotetext{
a Yildiz Technical University, Faculty of Science and Arts, Department of Chemistry, Davutpasa, 34220 Istanbul, Turkey, oziaksu@yahoo.com
} 
[3] (TLC), high performance liquid chromatography [4-5] (HPLC), raman spectroscopy [6-7], and spectrophotometry [8]. Unlike fluocortolone, many studies including the use of spectrophotometry [2,9], fluorimetry [10], TLC [11], liquid chromatography-mass spectrometry [12], sequential injection chromatography [13], HPLC [2,14-16], gas chromatography [17], chemometry [18] and electroanalytical methods [19-21] have been used for the determination of CIN. A HPLC method has been reported for the simultaneous determination of the three drugs [22].

In spite of widely use of chromatographic techniques, spectrophotometric analysis, being simple, inexpensive and fast, constitutes a highly convenient alternative approach for the determination of drugs in pharmaceutical formulations. However, the greatest difficulties with the conventional spectrophotometric methods arise when the analytes to be determined give partial or fully overlapped spectra.

In recent years, multivariate calibration methods such as principal component regression (PCR) and partial least squares (PLS) have been applied to overlapped spectra or chromatograms successfully [23-30]. All these techniques have the advantageous of using the full spectral information and not only a characteristic peak value. Moreover, they allow for a rapid determination of the components, and usually there is no need of a prior separation. However, the literature survey reveals that no chemometric methods have been reported for the analysis of these three drugs in combination.

In this study, PLS-2 calibration model was described for the spectrophotometric multicomponent analysis of synthetic ternary mixtures consisting of FCC, FCP and CIN and pharmaceutical formulation, suppository. In order to appraise the results obtained by proposed method, reported HPLC method was used [22]. The scientific novelty of the present work is that the PLS-2 method is simple, rapid and cheap compared with chromatographic method.

\section{RESULTS AND DISCUSSION}

In the last years, the chemometric methods such as classical leastsquares (CLS), PCR and PLS have become routine methods in multicomponent quantitative analysis [31-36]. The PLS calibration technique based on factor analysis can be performed in two different ways, PLS-1 and PLS-2. PLS-1 performs the optimization of the number of factors for only one component at a time. PLS-2 calculates the number of factors on all the components simultaneously and one weighed number of factors is optimized. Here, the PLS-2 version that is optimized for the simultaneous determination of FCC, 
FCP and CIN was implemented. This multivariate method involves a calibration step in which relation between spectra and component concentrations is estimated from a set of reference samples, and a prediction step in which the results of the calibration are used to estimate the component concentration in an unknown sample spectrum [25,34]. The theory and applications of this method were documented in detail in the literature [37-38].

The electronic absorption spectra of FCC, FCP and CIN in methanol (Figure 1) show that they overlap significantly. Thus, these compounds can not be analyzed in the presence of each other by a simple calibration procedure without prior separation. Therefore, PLS-2 was used to resolve the spectra and to determine each component in the ternary mixture of FCC, FCP and CIN.

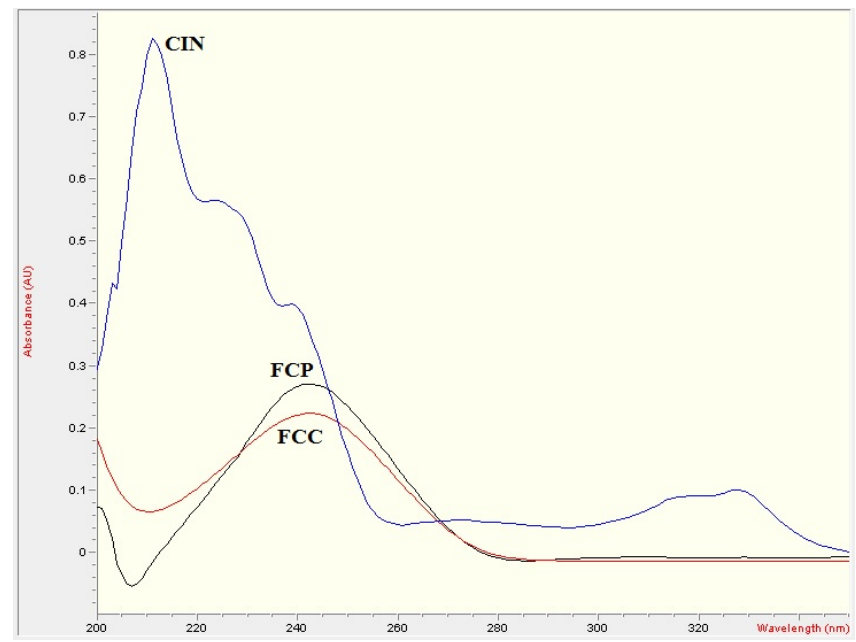

Figure 1. Absorption spectra of FCC $(6.3 \mu \mathrm{g} / \mathrm{mL})$, FCP $(6.1 \mu \mathrm{g} / \mathrm{mL})$ and $\mathrm{CIN}(10 \mu \mathrm{g} / \mathrm{mL})$ in methanol.

Table 1. Composition of the calibration sample

\begin{tabular}{|c|c|c|c|}
\hline Sample & $\mathrm{FCC}(\mu \mathrm{g} / \mathrm{mL})$ & $\mathrm{FCP}(\mu \mathrm{g} / \mathrm{mL})$ & $\mathrm{CIN}(\mu \mathrm{g} / \mathrm{mL})$ \\
\hline 1 & 4.5 & 5 & 8 \\
\hline 2 & 6.5 & 5 & 8 \\
\hline 3 & 8.5 & 5 & 8 \\
\hline 4 & 4.5 & 6 & 8 \\
\hline 5 & 6.5 & 6 & 8 \\
\hline 6 & 8.5 & 6 & 8 \\
\hline 7 & 4.5 & 7 & 8 \\
\hline 8 & 6.5 & 7 & 8 \\
\hline
\end{tabular}




\begin{tabular}{|c|c|c|c|}
\hline 9 & 8.5 & 7 & 8 \\
\hline 10 & 4.5 & 5 & 10 \\
\hline 11 & 6.5 & 5 & 10 \\
\hline 12 & 8.5 & 5 & 10 \\
\hline 13 & 4.5 & 6 & 10 \\
\hline 14 & 6.5 & 6 & 10 \\
\hline 15 & 8.5 & 6 & 10 \\
\hline 16 & 4.5 & 7 & 10 \\
\hline 17 & 6.5 & 7 & 10 \\
\hline 18 & 8.5 & 7 & 10 \\
\hline 19 & 4.5 & 5 & 12 \\
\hline 20 & 6.5 & 5 & 12 \\
\hline 21 & 8.5 & 5 & 12 \\
\hline 22 & 4.5 & 6 & 12 \\
\hline 23 & 6.5 & 6 & 12 \\
\hline 24 & 8.5 & 6 & 12 \\
\hline 25 & 4.5 & 7 & 12 \\
\hline 26 & 6.5 & 7 & 12 \\
\hline 27 & 8.5 & 7 & \\
\hline
\end{tabular}

For the PLS-2 calibration stage, 27 training samples were employed, conforming to $3^{3}$ full factorial design [39]. The composition data of solutions is listed Table 1. The spectra of this calibration set were recorded in the spectral region between 240 and $350 \mathrm{~nm}$ with $1 \mathrm{~nm}$ intervals. The optimum number of factors and important statistical parameters: The root-mean square deviation (RMSD), relative error of prediction (REP\%) and square of the correlation coefficent $\left(R^{2}\right)$ are summarized in Table 2.

Table 2. Statistical parameters for the calibration using PLS-2

\begin{tabular}{|c|c|c|c|}
\hline Parameters $^{*}$ & FCC & FCP & CIN \\
\hline Factors & 3 & 3 & 3 \\
\hline RMSD & 0.186 & 0.081 & 0.073 \\
\hline REP\% & 2.86 & 1.35 & 0.73 \\
\hline$R^{2}$ & 0.987 & 0.990 & 0.998 \\
\hline $\operatorname{LOD}(\mu \mathrm{g} / \mathrm{mL})$ & 0.31 & 0.22 & 0.13 \\
\hline $\mathrm{LOQ}(\mu \mathrm{g} / \mathrm{mL})$ & 1.05 & 0.74 & 0.43 \\
\hline
\end{tabular}




$$
\begin{gathered}
{ }^{*} \mathrm{RMSD}=\left[\frac{1}{m} \sum_{1}^{m}\left(c_{\text {act }}-c_{\text {pred }}\right)^{2}\right]^{1 / 2} ; \% \mathrm{REP}=\frac{100}{\bar{c}}\left[\frac{1}{m} \sum_{1}^{m}\left(c_{\text {act }}-c_{\text {pred }}\right)^{2}\right]^{1 / 2} \text { and } \\
R^{2}=1-\left(\sum_{1}^{m}\left(c_{\text {act }}-c_{\text {pred }}\right)^{2}\right) /\left(\sum_{1}^{m}\left(c_{\text {act }}-\bar{c}\right)^{2}\right)
\end{gathered}
$$

where $\bar{c}$ is the avarage component concentration in the m mixtures.

\section{Application to synthetic mixtures}

In order test to the quality of the proposed method, it was applied to the resolution of ternary synthetic mixtures containing different concentrations of three drugs. The composition of mixtures and the predictions of these synthetic samples are shown in Table 3 . As regards the results provided by PLS-2 on the synthetic sample set, good recoveries were obtained for FCC, FCP and CIN (Relative error of prediction (REP\%) values not exceed 15\%).

\begin{tabular}{|c|c|c|c|c|c|c|c|c|c|}
\hline & \multicolumn{3}{|c|}{ Mixture 1} & \multicolumn{3}{|c|}{ Mixture 2} & \multicolumn{3}{|c|}{ Mixture 3} \\
\hline Analyte & FCC & FCP & CIN & FCC & FCP & CIN & FCC & FCP & $\mathrm{CIN}$ \\
\hline $\begin{array}{l}\text { Added } \\
(\mu \mathrm{g} / \mathrm{mL})\end{array}$ & 4.5 & 5.0 & 8.0 & 6.5 & 6.0 & 10.0 & 8.5 & 7.0 & 12.0 \\
\hline $\begin{array}{l}\text { Found } \\
(\mu \mathrm{g} / \mathrm{mL})\end{array}$ & $\begin{array}{l}4.1 \\
4.7 \\
4.3\end{array}$ & $\begin{array}{l}5.4 \\
4.9 \\
5.2\end{array}$ & $\begin{array}{l}8.3 \\
8.2 \\
8.2\end{array}$ & $\begin{array}{l}6.6 \\
6.8 \\
6.9\end{array}$ & $\begin{array}{l}6.2 \\
5.9 \\
5.9\end{array}$ & $\begin{array}{c}10.1 \\
10.0 \\
9.9\end{array}$ & $\begin{array}{l}8.7 \\
9.2 \\
9.0\end{array}$ & $\begin{array}{l}6.5 \\
6.3 \\
6.5\end{array}$ & $\begin{array}{l}12.1 \\
12.1 \\
12.2\end{array}$ \\
\hline Mean & 4.4 & 5.2 & 8.2 & 6.8 & 6.0 & 10.0 & 9.0 & 6.4 & 12.1 \\
\hline Recovery\% & 98 & 104 & 103 & 105 & 100 & 100 & 106 & 91 & 101 \\
\hline RMSD & 0.4 & 0.4 & 0.2 & & & & & & \\
\hline REP\% & 6.2 & 6.7 & 2.0 & & & & & & \\
\hline
\end{tabular}

Table 3. Results obtained by applying PLS-2 to synthetic samples

Application to real samples

The PLS-2 method was used in the simultaneous determination of FCC, FCP and CIN in commercially avaliable suppository formulation. Satisfactory results were obtained for all drugs and were good agreement with the label claims (The recoveries are within the range $98.36-104.76 \%$ ). 
The results obtained by proposed method was statiscally compared with the literature method based on HPLC [22] by applying Student's $t$-test for accuracy and $F$-test for precision. The statistical results were summarized in Table 4. The results revealed that there is no significant difference between the proposed and reported method at the 95\% confidence level with respect to accuracy and precision. Consequently, the above results show that the proposed method can be successfully applied for simultaneous determination of FCC, FCP and CIN in real samples.

Table 4. Determination of FCC, FCP and CIN in suppository ${ }^{\mathrm{a}}$ using of PLS-2 and reference HPLC methods

\begin{tabular}{|c|c|c|c|c|c|c|}
\hline \multirow{2}{*}{\begin{tabular}{|c|}
$\mathrm{n} 1=\mathrm{n} 2=5$ \\
Analyte \\
(mg/suppository)
\end{tabular}} & \multicolumn{3}{|c|}{ PLS-2 } & \multicolumn{3}{|c|}{ HPLC } \\
\hline & FCC & FCP & CIN & FCC & FCP & $\mathrm{CIN}$ \\
\hline mean $\pm S D^{b}$ & $0.66 \pm 0.02$ & $0.60 \pm 0.01$ & $1.04 \pm 0.03$ & $0.64 \pm 0.01$ & $0.61 \pm 0.01$ & $\begin{array}{c}1.01 \pm 0 . \\
02\end{array}$ \\
\hline Recovery\% & 104.76 & 98.36 & 104.00 & 101.58 & 100.00 & 101.84 \\
\hline $\begin{array}{c}t \text { test of } \\
\text { significance }\end{array}$ & 2.01 & 1.57 & 1.90 & & & \\
\hline $\begin{array}{c}F \text { test of } \\
\text { Significance }\end{array}$ & 4.00 & 1.00 & 2.25 & & & \\
\hline$t_{8}{ }^{0,05}=$ & $=2.31$ & $F_{4,4}{ }^{0.05}=6.3$ & & & & \\
\hline
\end{tabular}

aUltraproct Suppository ${ }^{\circledR}$ (FCC $0.63 \mathrm{mg}$, FCP $0.61 \mathrm{mg}$, CIN $1.00 \mathrm{mg}$ )

bStandard deviation

\section{CONCLUSIONS}

The proposed method was applied to the simultaneous spectrophotometric analysis of FCC, FCP and CIN, in spite of a strong overlapping absorption spectra of these components in the wavelength range of $210-280 \mathrm{~nm}$. The overlapping was successfully resolved using the PLS-2 algorithm. According to the results obtained in this work, application of the proposed method was found to be adequately accurate, simple, fast and inexpensive for the simultaneous determination of FCC, FCP and CIN in ternary mixtures of synthetic and pharmaceutical samples. In addition, the proposed calibration method do not require any prior treatment, and optimization of conditions such as $\mathrm{pH}$, temperature, and flow rate in comparison with HPLC. 
In conclusion, PLS-2 multivariate calibration method can be recommended as a very suitable choice to resolve severe overlapped absorption spectra of drug mixtures and used as cheap and accessible alternative for routine quality control testing of common pharmaceutical formulations of FCC, FCP and CIN.

\section{EXPERIMENTAL SECTION}

\section{Chemicals and reagents}

FCC, FCP and CIN were obtained from Zeytaş Ltd., Istanbul, Turkey. Analytical grade methanol and acetic acid were purchased from Merck Company (Darmstadt, Germany). Ultra-pure water was obtained in the laboratory using a Milli-Q purification system from Millipore (Milford, MA, USA)

The "Ultraproct Suppository ${ }^{\circledR "}$ commercial samples were acquired from Turkey pharmacies. Each suppository was labeled to contain $0.63 \mathrm{mg}$ of FCC, $0.61 \mathrm{mg}$ of FCP and $1 \mathrm{mg}$ of CIN. The chemical structures of the drugs are shown in Figure 2.

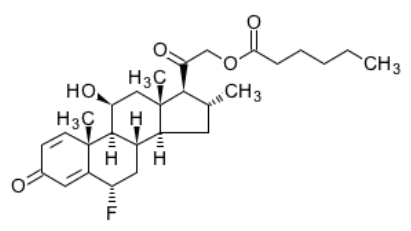

FCC

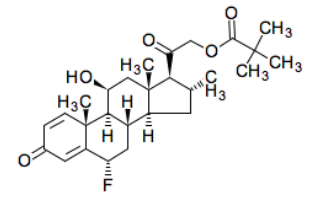

FCP

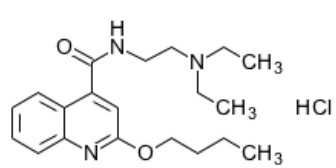

CIN

Figure 2. Molecular structures of the drugs analyzed

Instrumentation and software

Spectrophotometric measurements were performed with Agilent 8453 UV-Vis Spectrophotometer. PLS-2 was implemented using PLSToolbox software version 5.2 for use with MATLAB 11 .

HPLC measurements were carried out on a Shimadzu HPLC system equipped with a model LC20 AT pump unit, SPD-20A UV-Vis detector and C18 $(300 \mathrm{~mm} \times 3.9 \mathrm{~mm}) \mathrm{RP}$ column.

Preparation of standard solutions and calibration set

Stock standard solutions of the drugs $(100 \mu \mathrm{g} / \mathrm{mL})$ were prepared in methanol. Working solutions for calibration set were prepared by appropriate dilution of stock solutions with methanol. The calibration set for PLS-2 was generated by $3^{3}$ - full factorial design. The levels correspond to values in the 
range of $4.5-8.5 \mu \mathrm{g} / \mathrm{mL}$ for FCC, $5-7 \mu \mathrm{g} / \mathrm{mL}$ for FCP and $8-12 \mu \mathrm{g} / \mathrm{mL}$ for CIN. The absorbances were recorded in $1.00 \mathrm{~cm}$ cuvettes between 240 and 350 at every $1 \mathrm{~nm}$.

\section{Test samples for PLS-2}

For evaluation of proposed method, three concentration levels were used. These levels have been selected by considering the amounts of the analytes in the calibration range. Three group of test solutions were analysed applying the studied method three times.

\section{Sample preparation}

Ten suppositories accurately weighed, melted by stirring on a water bath to homogenize and than cooled. A portion of the homogenized suppositories equivalent to one suppository was transferred into a beaker, $30 \mathrm{~mL}$ methanol was added and melting was performed on a water bath. The solution was cooled, filtered into $100 \mathrm{~mL}$ volumetric flask and then diluted to volume with methanol.

\section{HPLC method}

The determination of the contents of FCC, FCP and CIN in suppository was also verified by reported HPLC method [22]. The mobile phase was methanol-water-acetic acid (72:26:2). The analysis was done under isocratic conditions at a flow rate of $1.3 \mathrm{~mL} / \mathrm{min}$ and the effluent was manitored by UV measurements at $240 \mathrm{~nm}$.

\section{REFERENCES}

1. M. Kerscher; S. William; P. Lehmann; Topical Treatment with Glucocorticoids, in Handbook of atopic eczema, 2nd. ed; J. Ring; B. Przybilla; T. Ruzicka; Newyork: Springer-Verlag, Berlin Heidelberg, 2006, pp.477-491.

2. A. El-Gindy; M. A. Korany; M. F. Bedair; J. Pharm. Biomed. Anal., 1998, 17, 1357-1370.

3. M. Amin; Anal. Chem., 1987, 328, 114-116.

4. S. Rohatagi; U. Tauber; K. Richter; H. Derendorf; J. Clin. Pharmacol.,1996, 36, 311-314.

5. O. Cudina; J. Brboric; Z. Vujic; D. Radulovic; S. Vladimirov; Farmaco, 2000, 55, 125-127.

6. A.P. Gamot; G. Vergoten; M. Saudemon; G. Fleury; Talanta, 1985, 32, 373-382.

7. A.P. Gamot; G. Vergoten; M. Saudemon; G. Fleury; J. Barbillat; Talanta, 1986, 33, 295-298. 
MULTIVARIATE CALIBRATION METHOD FOR SIMULTANEOUS ESTIMATION OF ...

8. H.M. Lotfy; S.M. Tawakkol; N.M. Fahmy; M.A. Shehata; Spectrochim. Acta A, 2015, 136, 937-952.

9. N.T. Abdel-Ghani; F.A. Ahmed; A.A. Mohamed; I/ Farmaco, 2005, 60, 419-424.

10. S. Essig; K.A. Kovar; Chromatographia, 2001, 53, 321-322.

11. M.M. Mohammad; N.H. Zawilla; F.M. El-Anwar; S.M. Aly; J. AOAC Int., 2007, 90, 405-413.

12. T. Saito; S. Morita; I. Kishiyama; S. Miyazaki; A. Nakamoto; M. Nishida; A. Namera; M. Nagao; J. Chromatogr. B Analyt. Technol. Biomed. Life Sci., 2008, 872, 186-190.

13. D. Satinsky; P. Chocholous; O. Valova; L. Hanusov; P. Solich; Talanta, 2013, 114, 311-317.

14. S. Izumoto; Y. Machida; H. Nishi; K. Nakamura; H. Nakai; T. Sato; J. Pharm. Biomed. Anal., 1997, 15, 1457-1466.

15. M.A. El-Sayed; Biomed. Chromatogr., 2007, 21, 491-496.

16. R.D. Barbosa; A. Klassen; P.D. Marcato; M. Franz-Montan; R. Grillo; L.F. Fraceto; E. Paula; Lat. Am. J. Pharm., 2013, 32, 1362-1369.

17. T. Ohshima; T. Takayasu; J. Chromatogr. B Biomed. Sci. Appl., 1999, 726, $185-$ 194.

18. C. Soto; D. Contreras; M.I. Toral; L. Basaez; J. Freer; J. Chil. Chem. Soc., 2009, 54, 113-118.

19. H. Satake; T. Miyata; S. Kaneshina; Bulletin Chem. Soc. Japan, 1991, 64, 30293034.

20. S. Komorsky-Lovric; N. Vukasinovic; R. Penovski; Electroanalysis, 2003, 15, 544-547.

21. A.A. Ensafi; A.R. Allafchian; Bull. Korean Chem. Soc., 2011, 32, 2722-2726.

22. B. Aşçı; M. Koç; Current Pharm. Anal., 2019, 15, 32-38.

23. M.S. Collado; V.E. Mantovani; C.H. Goicoechea; A.C. Olivieri; Talanta, 2000, 52, 909-920.

24. A. El-Gindy; A.A. Ashour; L. Abdel-Fattah; M.M. Shabana; J. Pharm. Biomed. Anal., 2001, 25, 923-931.

25. M.J. Culzoni, M.M. De Zan, J.C. Robles, V.E. Mantovani, H.C. Goicoechea, J. Pharm. Biomed. Anal., 2005, 39, 1068.

26. S. Şahin; C. Demir; Ş. Güçer; Dyes and Pigments, 2006, 73, 368-376.

27. R.M. Maggio; P.M. Castellano; T.S. Kaufman; Anal. Bioanal. Chem., 2008, 391, 2949-2955.

28. N. Yongnian; Y. Wang; S. Kokot; Spectrochim. Acta A, 2008, 70, 1049-1059.

29. E. Dinç; D. Balenau; G. Ioele; M. De Luca; G. Ragno; J. Pharm. Biomed. Anal., 2008, 48, 1471-1475.

30. C. Zapata-Urzua; M. Perez-Ortiz; M. Bravo; A.C. Olivieri; A. Alvarez; Talanta, 2010, 82, 962-968.

31. S. Riahi; F. Hadiloo; S.M. Milani; N. Davarkhah; M.R. Ganjali; P. Norouzi; P.A. Seyfie; Drug Test Anal., 2011, 3, 319-324.

32. Ö.A. Dönmez; B. Aşçı; A. Bozdoğan; S. Sungur; Talanta, 2011, 83, 1601-1605.

33. Ş. Dinç; Ö.A. Dönmez; B. Aşçı; A. Bozdoğan; J. Liq. Chromatogr. Relat. Technol., 2014, 37, 560-571. 
34. A.M. El-Kosasy; O. Abdel-Aziz; N. Magdy; N.M. El Zahar; Spectrochim. Acta A, 2016, 157, 26-33.

35. M.F. Abdel-Ghany; L.A. Hussein; M.F. Ayad; M.M. Youssef; Spectrochim. Acta A., 2017, 171, 236-245.

36. H. Khajehsharifi; Z. Eskandari; N. Sareban; Arabian J. Chem., 2017, 10, 141-147.

37. H. Martens; T. Naes; Multivariate Calibration, Wiley, Chichester,U.K, 1989.

38. P. Geladi; B.R. Kowalski; Anal. Chim. Acta, 1986, 185, 1-17.

39. D.C. Montgomery; Design and Analysis of Experiments, Wiley, Newyork, 1997. 